\title{
Live and Let Live: Integrating Lived Experience in Participatory Healthcare Design
}

\author{
Anna-Sophie Oertzen ${ }^{\mathrm{a}, \mathrm{b}}$, Josina Vink ${ }^{\mathrm{c}, \mathrm{d}, \mathrm{e}}$, Gaby Odekerken-Schröder ${ }^{\mathrm{a}}$, Birgit Mager ${ }^{\mathrm{b}}$, Salomé \\ Azevedo f,g

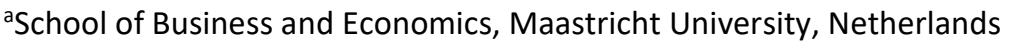 \\ ${ }^{\mathrm{b} K o ̈ l n ~ I n t e r n a t i o n a l ~ S c h o o l ~ o f ~ D e s i g n, ~ T e c h n i c a l ~ U n i v e r s i t y ~ o f ~ A p p l i e d ~ S c i e n c e s ~ C o l o g n e, ~ G e r m a n y ~}$ \\ 'Oslo School of Architecture and Design, Norway \\ ${ }^{\mathrm{d} C e n t r e ~ f o r ~ S e r v i c e ~ R e s e a r c h, ~ K a r l s t a d ~ U n i v e r s i t y, ~ S w e d e n ~}$ \\ EExperio Lab, County Council of Värmland, Sweden \\ fUCP - Católica Lisbon School of Business and Economics, Portugal \\ gPatient Innovation Association, Portugal \\ *Corresponding author e-mail: anna.sophie.oertzen@gmail.com
}

\begin{abstract}
:
Despite growing interest in participatory approaches to healthcare design, the integration of people's lived experience - direct, first-hand understanding of a certain condition, situation, or identity - remains a key challenge to meaningful participation. This research seeks to investigate the multifaceted elements involved in leveraging lived experiences and to describe strategies to support their integration in participatory healthcare design initiatives. Through an interview study, the authors identify underlying tensions associated with leveraging lived experiences in healthcare design and assemble strategies for integrating different degrees of lived experience. In doing so, this research offers insights for designers regarding possible ways to support the integration of people's lived experience amid complex healthcare contexts.
\end{abstract}

Keywords: healthcare; participatory design; lived experience; tensions and strategies; co-creation

\section{Introduction}

Participatory approaches to healthcare design that involve staff, patients, and families in the cocreation of care are increasingly recognized as a necessity (Cottam \& Leadbeater, 2004; World Health Organization, 2018). Involving these various actors in healthcare design initiatives can improve treatment outcomes and healthcare experiences (Spanjol et al., 2015; Vahdat et al., 2014), and it is a fundamental element of participatory healthcare design (Bate \& Robert, 2006). To co-create care that is inclusive and tailored to the needs of the affected people, purposefully integrating their lived experience during participatory design efforts is a critical necessity (Berry, 2019; Vink \& Oertzen, 2018). This research defines lived experience as a direct, first-hand understanding of a certain 
condition, situation, or identity. Lived experience is holistic, shaped by contextual factors, and unfolds over time (Gallan et al., 2019). For example, a woman who has survived breast cancer has specific lived experiences that involve a deep, personal understanding of what it feels like to be diagnosed, receive treatment, and continue living after cancer (Williams \& Jeanetta, 2016). Her lived experience can inform the design of services that women with breast cancer require, for instance by inviting the woman to co-creation workshops to gather ideas, by asking her to provide feedback on early prototypes of a new service, or by investing resources for her to innovate for herself.

Despite considerable attention to the potential benefits of engaging different actors in healthcare design, little research details the approaches for meaningfully integrating lived experiences into design processes (Danaher \& Gallan, 2016). Without an in-depth understanding of the nature of leveraging lived experience in healthcare design, ill-informed efforts to involve staff, patients, and families create a risk of tokenizing those involved by marginalizing their contribution. This leads to establishing a participation façade, which (1) reinforces existing power imbalances as well as the preexisting perspectives and strategies of people with dominant roles, (2) increases patient alienation and frustration, and (3) may even lead to serious healthcare failings (Farrington, 2016; Ocloo \& Matthews, 2016). Therefore, the objectives of this research are to investigate the multifaceted elements involved in leveraging lived experience in healthcare design, and to develop strategies to support such integration in participatory healthcare design initiatives.

\section{Background}

In the past decade, healthcare organizations worldwide have invested more in design, in efforts to catalyse transformations that acknowledge the importance of the human experience (Hargraves, 2018; Mager et al., 2017). This increasing interest in design is fuelled in part by the demand for significant changes to healthcare models, such as the World Health Organization advocating for a transition toward integrated, people-centred healthcare (World Health Organization, 2018). Design promises a means to help healthcare systems transition from a biomedical model toward a peoplecentred care approach that emphasizes seeing the patient as a person in context (Malmberg et al., 2019). People-centred healthcare requires shifting from a narrow focus on a specific disease or body part toward active co-creation of healthcare experiences, including collaborative activities among patients, their families, healthcare staff, and others (Danaher \& Gallan, 2016; McColl-Kennedy et al., 2012; Oertzen et al., 2018; World Health Organization, 2018).

As design is positioned as a catalyst for this paradigmatic shift toward co-creation in healthcare, there has been a growing emphasis on participatory healthcare design processes (Cottam \& Leadbeater, 2004; Freire \& Sangiorgi, 2010). Participatory design is grounded in the fundamental notion that "those affected by a design should have a say in the design process" (Ehn, 2008, p. 94). Participatory healthcare design processes give staff, patients, and families opportunities to reflect on and shape their healthcare experiences and provide input into the redesign of the overall system (Donetto et al., 2015). The resulting range of processes might include inviting diverse people to workshops to inform the design of prosthetics (Hussain et al., 2012), or partnering with patients and staff to co-design a new service for people living with diabetes (Freire \& Sangiorgi, 2010). Thus, participatory healthcare design processes inherently rely on the lived experience of people, who have unique understanding of their own particular circumstances (Bate \& Robert, 2006).

Even as the number of participatory healthcare design initiatives increases, meaningfully leveraging lived experiences in these design processes remains a challenge. First, though lived experience has immense value in terms of deepening understanding of people's needs and the context, it can be 
difficult to combine different knowledge sources and perspectives (Lehoux et al., 2011; Trischler et al., 2018). Conflict may arise across multiple truth regimes, such as when integrating the lived experience of patients with traditional sources of expertise, such as doctors' knowledge (Carr et al., 2009; Sellen, 2017). Second, some people experience additional barriers to participation, such as patients with dementia, who require a thoughtful and sensitive approach to be able to collaborate (Tobiasson et al., 2015). Third, recruiting diverse patients to participate in lengthy healthcare design initiatives is difficult, such that design efforts often wind up relying on self-selecting, pre-existing patient groups with a narrow subset of lived experience (Farrington, 2016). Fourth, many healthcare design initiatives fail to acknowledge the power dynamics related to leveraging lived experience in healthcare contexts, such that they risk reproducing oppressive, exclusive practices (Donetto et al., 2015).

Although there are various existing tools that evaluate participation (e.g., Arnstein, 1969; IAP2, 2018), they do not account for the specificities of integrating lived experiences in the process of participation. Determining how to leverage the lived experience of different people in participatory design processes is particularly important in healthcare contexts, in which others cannot gain an accurate, holistic understanding of what it feels like to have a certain illness by using a product or service or even engaging in day-long simulations. That is, an in-depth understanding of ways to leverage lived experience is critical for advancing healthcare design to support people's meaningful, authentic participation, which ultimately facilitates the transition toward integrated, people-centred healthcare.

\section{Methodology}

\subsection{Data Collection}

Noting the lack of empirical insights into leveraging lived experience in healthcare design, this study employs in-depth, semi-structured interviews to capture rich existential-phenomenological descriptions of people's life-worlds (Thompson et al., 1990). Phenomenology is well-suited to explore complex issues that necessitate deeper insights beyond surface responses (Goulding, 2005), as it seeks to extract people's lived experience based on the way a person describes their experience and perceives meaning in this experience (Bevan, 2014). In phenomenological research, the sampling frame is purposive, as participants are selected based on their lived experience (Goulding, 2005). To this end, the authors of this research immersed themselves in two healthcare organizations to gain a deeper meaning of the general context and the diverse spectrum of lived experience of different people. The active immersion lasted between five months to one year at the local premises of Experio Lab in Sweden and Patient Innovation in Portugal. Both initiatives represent examples of the growing global movement toward participatory approaches in healthcare design (Mager et al., 2017). Healthcare design in Experio Lab is typically initiated from inside the healthcare system by designers and healthcare professionals; on the other hand, in Patient Innovation it is driven and initiated by patients and family caregivers. Conducting interviews across both contexts helps account for the diversity of healthcare design processes and the different constellations by which lived experiences can be integrated.

Over a 12-week period, semi-structured interviews were conducted with 23 participants: 5 patients, 7 designers, 7 family caregivers, and 4 healthcare professionals. Interviews focused on one of the 18 different participatory healthcare initiatives that participants had been involved in. For instance, the authors interviewed patients and family caregivers, who had led the design of innovations focused on diverse situations, such as bladder control, supporting breast cancer recovery, and helping people 
with visual impairments. Among others, the interviewed designers and healthcare professionals had facilitated co-creation processes to innovate maternity care, mental health, or recovery from a heart attack. An ethical review committee approved the research protocol and all participants signed an informed consent form before answering any questions. The interviews were audio recorded and lasted 64 minutes on average. Participants were asked to discuss the healthcare design initiative they participated in, the other people involved, how these collaborations took place, the role of lived experience in the process, the challenges they encountered in leveraging their lived experience, and lessons learned.

\subsection{Data Analysis}

Thompson's (1997) pragmatic considerations of hermeneutic analysis were used to explore, thematise, and synthesize the existential-phenomenological descriptions of people's lived experience. Hermeneutic analysis interprets each interview individually after which common patterns, or so-called themes, are identified across interviews (Thompson et al., 1990). During the first stage, interviews were summarized upon their completion and audio files were transcribed verbatim (321 single-spaced transcript pages). Next, the summaries and transcripts were read to get an overall understanding of the data and the underlying narratives. In the second stage, two members of the author team worked independently and iteratively on intratext analysis to locate and mark significant text segments as facets of integrating lived experience and approaches to integrating lived experience. Findings were contrasted and complemented between the researchers to support researcher triangulation (Flick, 2018). The third stage included an iterative part-to-whole analysis, whereby significant text segments were related to the whole and interpretations were continuously revised (Thompson, 1997). Based on this intertext analysis, common themes were established that are meaningful to the research objectives. Finally, in the fourth stage, the author team acknowledged that all identified themes are a fusion of horizons between the participants' descriptions and the researchers' interpretations (Goulding, 2005; Thompson, 1997). To ensure the themes' credibility (Thompson et al., 1990), they were critically evaluated by members of Experio Lab and Patient Innovation, which resulted in adaptations of the wording.

\section{Findings}

\subsection{Six Underlying Tensions of Leveraging Lived Experience}

The authors encountered several contradicting patterns that are synthesized into six tensions when integrating people's lived experience in participatory healthcare design initiatives: in/ability, $\mathrm{im} /$ partiality, dis/connection, in/direct, dis/similarity, and mis/understanding. Table 1 defines each tension and provides a practical example and illustrative quotes from the interviews. A slash is used in the name of each tension to acknowledge that these tensions include the facets that are often seen as opposing, yet they are not necessarily dichotomous. The tensions are also not mutually exclusive, as they are often interconnected and influence one another. These tensions reveal the inherent challenges and nuances that require thoughtful navigation when leveraging lived experience in healthcare design. 
Table 1. Underlying tensions of leveraging lived experience in participatory healthcare design

\begin{tabular}{|c|c|c|c|}
\hline Tension & Definition & Practical example & Illustrative quotes \\
\hline In/ability & $\begin{array}{l}\text { The contradiction between people } \\
\text { being uniquely capable of } \\
\text { leveraging their first-hand } \\
\text { experience, but also facing } \\
\text { significant barriers that limit their } \\
\text { capacity to do so. }\end{array}$ & $\begin{array}{l}\text { A patient having relevant lived } \\
\text { experience, but having problems } \\
\text { sharing it with others due to } \\
\text { memory loss, trauma, or stigma. }\end{array}$ & $\begin{array}{l}\text { "It's hard to remember what your concerns were when } \\
\text { you were pregnant after you have your baby." } \\
\text { "You may not remember what happened because you } \\
\text { were really depressed." }\end{array}$ \\
\hline $\mathrm{Im} /$ partiality & $\begin{array}{l}\text { The divide between using personal } \\
\text { feelings and perspectives and the } \\
\text { need for objectivity and acting } \\
\text { based on facts. }\end{array}$ & $\begin{array}{l}\text { A designer, who is also a mother, } \\
\text { trying to facilitate the co-creation } \\
\text { of a maternity care service } \\
\text { without integrating her own lived } \\
\text { experience. }\end{array}$ & $\begin{array}{l}\text { "I often struggle what's personal and what's professional } \\
\text { and I often feel like, oh no, now I'm unprofessional again } \\
\text { because I'm sharing too much." } \\
\text { "It's hard to put yourself aside, but that's what a designer } \\
\text { has to do" }\end{array}$ \\
\hline Dis/connection & $\begin{array}{l}\text { The push and pull between being } \\
\text { too attached or too detached to } \\
\text { the mission or context of the } \\
\text { design effort as a result of a lived } \\
\text { experience. }\end{array}$ & $\begin{array}{l}\text { A father's lived experience driving } \\
\text { him to innovate for his child's } \\
\text { well-being, but at the same time } \\
\text { wearing him out physically and } \\
\text { emotionally. }\end{array}$ & $\begin{array}{l}\text { "The experience obviously makes it different, it makes it a } \\
\text { mission." } \\
\text { "I don't want to work with projects related to that because } \\
\text { it's too close to heart." }\end{array}$ \\
\hline In/direct & $\begin{array}{l}\text { Challenges related to having } \\
\text { people with lived experience } \\
\text { present to share their knowledge } \\
\text { versus secondarily "presencing" } \\
\text { them through empathic methods. }\end{array}$ & $\begin{array}{l}\text { A designer fictionally presencing } \\
\text { patients through empathic } \\
\text { methods, such as role-playing, } \\
\text { but not capturing all aspects of } \\
\text { patients' lived experience. }\end{array}$ & $\begin{array}{l}\text { "There's a huge benefit in being there in person. There's a } \\
\text { lot of communication that happens through body } \\
\text { language." } \\
\text { "It's easy to think that you know what the patients feel } \\
\text { about the whole journey and it's very good to have them } \\
\text { there to talk directly ... that they can be able to talk for } \\
\text { themselves and not that someone talks for them." }\end{array}$ \\
\hline Dis/similarity & $\begin{array}{l}\text { The contradiction between seeing } \\
\text { someone's lived experience as } \\
\text { related to someone else's } \\
\text { experience versus recognizing that }\end{array}$ & $\begin{array}{l}\text { A healthcare professional wanting } \\
\text { to integrate the lived experience } \\
\text { of patients to co-create a mental } \\
\text { health service, but struggling to }\end{array}$ & $\begin{array}{l}\text { "My story is the same story of } 85 \% \text { of the ... community." } \\
\text { "Everyone is very different. I mean, the issues experienced } \\
\text { by one person are not necessarily the same as the } \\
\text { experience by the next person. So we'd still need to go out }\end{array}$ \\
\hline
\end{tabular}




$\begin{array}{lll}\begin{array}{l}\text { every experience is unique and } \\ \text { different. }\end{array} & \begin{array}{l}\text { integrate the broad spectrum of } \\ \text { people's lived experience. }\end{array} & \begin{array}{l}\text { and speak to a wider audience, even if we had one person } \\ \text { [with lived experience in the team]." }\end{array}\end{array}$

Mis/understanding Being able to comprehend the lived experience of other people, but also considering it impossible to wholly know and comprehend someone else's experience.
A patient pointing out the necessity of being included in cocreating breast cancer support, because other people can only relate but not truly understand her lived experience.
"There's no way somebody can understand."

"I haven't had that in my life but I've had experiences of close relatives or family where the body has been affected a lot. ... I feel like it's somehow embodied in me. I've experienced the body being fragile."

Table 2. Strategies for integrating lived experience in participatory healthcare design

\begin{tabular}{|c|c|c|c|}
\hline Strategy & Definition & Practical example & Illustrative quotes \\
\hline $\begin{array}{l}\text { Simulati } \\
\text { ng }\end{array}$ & $\begin{array}{l}\text { Staging a temporary process of } \\
\text { mimicking or replicating a } \\
\text { particular lived experience }\end{array}$ & $\begin{array}{l}\text { Role-playing a certain } \\
\text { situation with people } \\
\text { who have not } \\
\text { experienced the situation }\end{array}$ & $\begin{array}{l}\text { "Then we did role-playing, so one in each group was the patient and they did a } \\
\text { scenario that they made up themselves." } \\
\text { "The way we did it, because we didn't have any patients in the room, was that I } \\
\text { was both. I was both the patient and also the moderator." }\end{array}$ \\
\hline $\begin{array}{l}\text { Presenci } \\
\text { ng }\end{array}$ & $\begin{array}{l}\text { Sharing second-hand } \\
\text { perspectives on lived } \\
\text { experience in the absence of } \\
\text { someone with relevant lived } \\
\text { experience present }\end{array}$ & $\begin{array}{l}\text { Drawing an empathy map } \\
\text { of people with lived } \\
\text { experience to make them } \\
\text { "present" in the room }\end{array}$ & $\begin{array}{l}\text { "We started with the empathy map, because we wanted to lift the target group } \\
\text { into the room to have them present." } \\
\text { "I am responsible for telling [the patients'] story in a way that maybe they are } \\
\text { not capable of or maybe they are not listened to." }\end{array}$ \\
\hline $\begin{array}{l}\text { Templat } \\
\text { ing }\end{array}$ & $\begin{array}{l}\text { Creating a standardized } \\
\text { procedure or format in which } \\
\text { people can share their lived } \\
\text { experience }\end{array}$ & $\begin{array}{l}\text { Filling in the blank spaces } \\
\text { in a provided document } \\
\text { to template people's } \\
\text { experience }\end{array}$ & $\begin{array}{l}\text { "I felt the workshop was very controlled. It was even the start of a phrase, like } \\
\text { the first words were set and then they were going to fill that in." } \\
\text { "We gave them papers with pre-printed questions." }\end{array}$ \\
\hline
\end{tabular}


Sharing A one-way process of directly communicating one's own lived experience, of value for others

\section{Someone sharing their own lived experience through interviews}

\begin{tabular}{ll}
\hline Exchang & A multi-directional process of \\
ing & $\begin{array}{l}\text { sharing and relating the lived } \\
\text { experience of several people }\end{array}$
\end{tabular}

\begin{tabular}{ll}
\hline Allying & $\begin{array}{l}\text { On-going partnership and } \\
\text { corresponding support between } \\
\text { people with relevant lived } \\
\text { experience and others }\end{array}$
\end{tabular}

Resourci Providing people with lived ng
Reciprocal dialogue among diverse people with similar and different lived experience to test and improve an innovation

A collaboration between someone with lived experience and other people to develop an innovation

\section{Using resources from} others to design for oneself as an entrepreneur
"I have this person that I call Lisa. ... She is telling the story and we listen to when she talked about how her life had been."

"We went to this day with midwives ... just to listen in and to get some voices from midwives about their role and how they see the future of midwifery."

"It's important that you get new people involved that have not been part of it before, because very soon you take something for granted."

"During the interviews ... when you're alone with this woman and her story, she's also very alone with her story. But when we put women together making them share stories, it's more about empowering each other. It becomes more like a shared experience."

"We decided to do everything under equality. ... Our interests are perfectly aligned. ... We like to collaborate and we both don't like to fight."

"I think that both sides have to be open and honest about what they're expecting from a collaboration, and what they want to achieve out of it."

"They need to know what you want, and they put it to work."

"I was the perfect patient to create it, or the perfect patient to test it, but when it came to the business side, I drew on nothing except common sense and faith ... so I had to reach out to the Washington DC attorney, who ... pulled it off for us." 


\subsection{Strategies to Leverage Lived Experience in Healthcare Design}

During the interviews, many participants noted several conscious and unconscious approaches to dealing with the tensions they faced when integrating their own and others' lived experience. Grounded in these observations, the authors assembled seven strategies of integrating lived experience in participatory healthcare design initiatives. Table 2 provides an overview of these strategies, which are not mutually exclusive and can be combined, in ascending order from the lowest to the highest levels of liberty that the strategy enables for the people that have lived experience relevant to the healthcare initiative.

Integrating patients or family caregivers to leverage their first-hand experience in healthcare initiatives can be challenging for various reasons, such as memory loss or the pain of remembering. In these cases, designers or healthcare professionals may try to temporarily employ the "simulating" strategy to replicate the lived experience of others, such as by role-playing a certain situation. Although a viable approach if the people that the healthcare initiative targets cannot be safely engaged, it runs the risk of falsely representing their lived experience or projecting other people's mental models onto their experience.

The second strategy, "presencing", also does not directly include the active participation of the people with lived experience targeted by the respective healthcare initiative. With this approach, people use empathy and knowledge from their second-hand experience to represent others. Storytelling is commonly used to instil a sense of presence, which helps people understand and design for others and the situations they face. Although this strategy integrates the lived experience of others indirectly, it draws only on second-hand knowledge, which may still lead to false representations of people's lived experience.

"Templating" is the first strategy that directly integrates first-hand, lived experience in participatory healthcare design initiatives. It provides a structured procedure or format for documenting people's lived experience, such as a standardized form with blank spaces that encourages people to report their own experience. This approach produces focused and structured data, but first-hand experience is often challenging to communicate in such a controlled and restricted format, and the data gathered inherently reflect the assumptions of the people who created the format for sharing.

The fourth strategy, "sharing", allows for the integration of first-hand knowledge in a less restricted and controlled format by asking people to directly communicate their lived experience, such as during interviews. The result is a more in-depth understanding of others' lived experiences. However, it still only offers a partial account of the first-hand perspective because such knowledge sharing generally is confined to a few interviews, one-off storytelling, or one-time workshop participation. This strategy also creates a potential risk of misinterpretation, because of the lack of clarification and dialogue in a one-way sharing process.

"Exchanging" elevates the integration of lived experience from one-directional communication to a multi-directional process of reciprocal communication. It comprises dialogue among two or more people who share similar or different lived experiences. With this strategy, people can better understand the first-hand knowledge associated with multiple perspectives, and people with lived experience can contextualize their experience relative to those of others. For example, some patients described designing an initial prototype of a solution to meet their needs, then asking other people in a similar situation to try it and give feedback. However, the duration of this strategy is typically relatively short and allows for limited exchanges of other resources. 
Unlike the prior strategies, the sixth strategy "allying" is long-term in nature. People engage in continuous partnerships with others and receive on-going support. For example, those with firsthand knowledge might participate throughout the course of a healthcare initiative that is steered by a designer. As another example, people with lived experience could design for themselves and others, while closely partnering over the long-term with others to access the support, knowledge, tools, or funding that they lack. This form of partnering leads to continuous sharing of experience, but it can be slow and resource consuming, and power dynamics may continue to constrain how lived experience is integrated.

Finally, "resourcing" comprises the highest level of liberty for people with lived experience who are the main beneficiaries of the healthcare initiative. This strategy provides people with lived experience with the assets they need to design the change they seek. People might take control over designing an innovation that improves their well-being while co-creating with others. With this strategy, people with lived experience often become user innovators and entrepreneurs, who lead the development of the services and systems that affect them. In many cases, the adoption of this strategy was born out of necessity. Patients who need specific solutions that are not readily available on the market may decide to develop them on their own, which usually requires resources from others. In some cases though, resourcing is not possible or desirable, whether due to the graveness of patients' illness or policy barriers. Furthermore, providing resources without ongoing allyship and connections to larger networks limits the potential influence of such healthcare initiatives.

\section{Discussion}

Previous research recognizes the importance of leveraging lived experience (Cipolla \& Bartholo, 2014; Vink \& Oertzen, 2018) to reduce the potential risk of tokenizing people in participatory healthcare design initiatives (Farrington, 2016). Despite recognizing the challenging nature of integrating lived experience, research to date offers limited insights into how practitioners can navigate these challenges and meaningfully integrate lived experience within the design process (Danaher \& Gallan, 2016; Sellen, 2017; Tobiasson et al., 2015; Trischler et al., 2018). In response, this research identifies six underlying tensions of integrating lived experience in participatory healthcare design initiatives, with influences on one another and that vary depending on the situation (Figure 1). Grounded in participants' conscious and unconscious approaches to dealing with the complexity of leveraging lived experience, the authors assembled seven strategies that are often combined as responses to different tensions, again depending on the context. The strategies are displayed on a spectrum corresponding to increasing levels of autonomy of the people with relevant lived experience. Although the strategies used to integrate lived experience are influenced by the tensions, the strategies employed also affect the tensions present during participatory healthcare initiatives. 


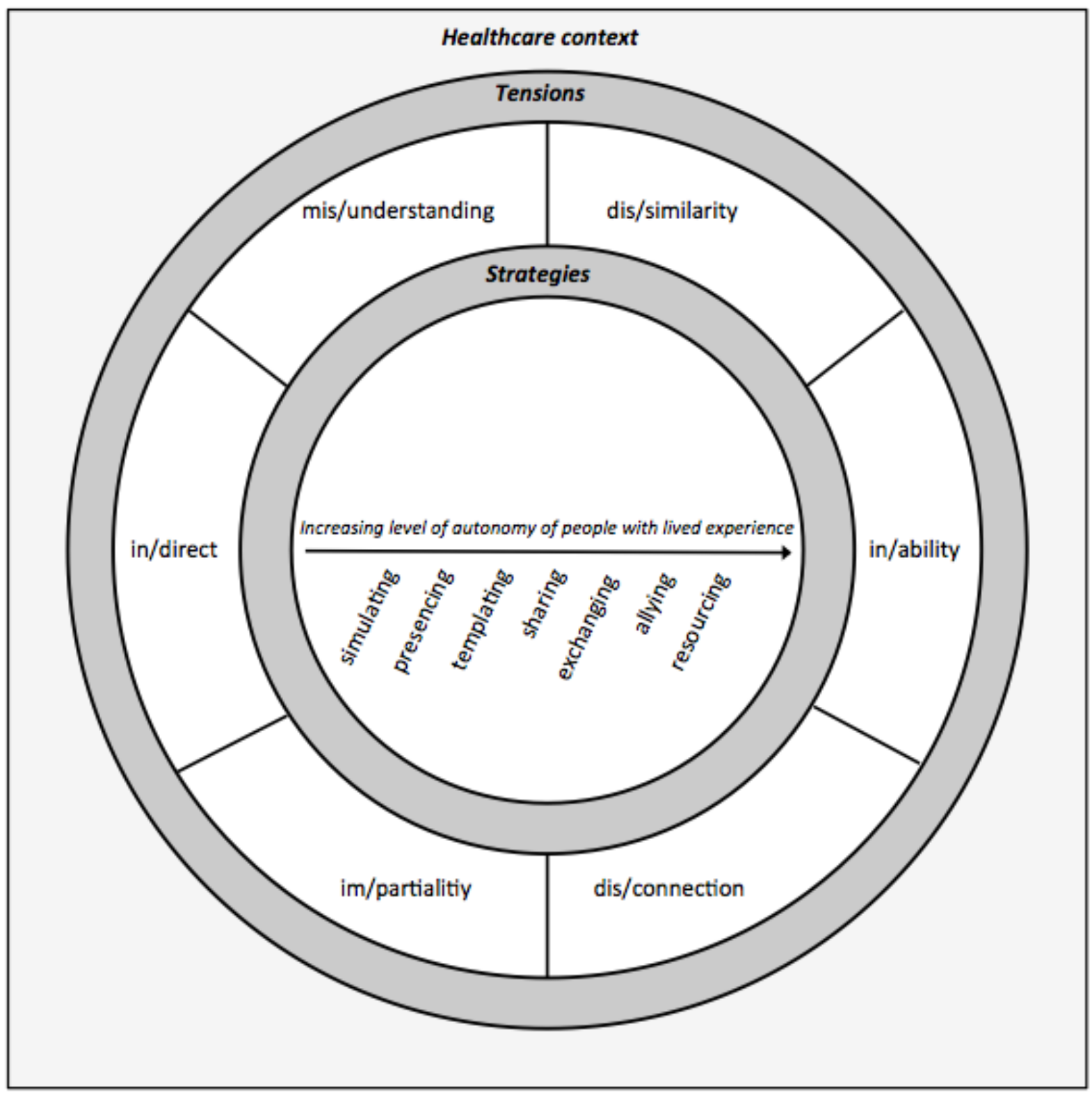

Figure 1. Conceptual framework of the dynamics of integrating lived experience in participatory healthcare design initiatives

This framework helps explain the limitations of existing participatory design initiatives. The six tensions identified help to contextualize the key challenges of leveraging lived experience, including those suggested by relevant prior literature. For example, Trischler et al. (2018) indicate the difficulty of combining different knowledge sources, and Sellen (2017) suggests that conflict might arise from working with multiple truth regimes. These challenges reflect the mis/understanding tension, because different people struggle to comprehend and accept the lived experience of others. The $\mathrm{im} /$ partiality tension may add to this complexity, resulting from the contradiction between the acceptability of subjective perspectives and objective reasoning. The conceptual framework further illustrates that these tensions influence the strategies used when co-creating in a particular healthcare context. In outlining these strategies and concrete practices, such as role-playing or workshops to enact them, the authors identify practical ways to meaningfully integrate varying degrees of lived experience, for instance the lived experience of patients and family caregivers in healthcare innovation initiatives (Berry, 2019; McColl-Kennedy et al., 2017; Ocloo \& Matthews, 2016). Furthermore, this framework provides a basis on which both researchers and practitioners 
can thoughtfully navigate and expand on the strategies for integrating lived experience in ways that are most appropriate for a given context.

\section{Conclusion}

This research phenomenologically explored the complex dynamics involved in integrating lived experience in participatory healthcare design initiatives. To clarify the multifaceted elements involved in leveraging lived experience and to provide strategies that support the integration of lived experience in participatory healthcare design initiatives, the authors conducted a qualitative interview study with 23 participants that included patients, designers, family caregivers, and healthcare professionals involved in participatory healthcare initiatives in different contexts. After hermeneutically analysing the data, the authors found six underlying tensions of integrating lived experience: in/ability, im/partiality, dis/connection, in/direct, dis/similarity, and mis/understanding. After examining people's existing conscious and unconscious approaches, seven strategies for leveraging different degrees of lived experience were assembled: simulating, presencing, templating, sharing, exchanging, allying, and resourcing. The explication of these tensions and strategies provides a foundation and vocabulary for more nuanced discussion and strategic practices in relation to leveraging lived experience in participatory healthcare design.

\section{References}

Arnstein, S. R. (1969). A ladder of citizenship participation. Journal of the American Institute of Planners, 35(4), 216-224.

Bate, P., \& Robert, G. (2006). Experience-based design: from redesigning the system around the patient to co-designing services with the patient. BMJ Quality \& Safety, 15(5), 307-310.

Berry, L. L. (2019). Service innovation is urgent in healthcare. AMS Review, 9(1/2), 1-15.

Bevan, M. T. (2014). A method of phenomenological interviewing. Qualitative Health Research, 24(1), 136-144.

Carr, V., Sangiorgi, D., Büscher, M., \& Junginger, S. (2009). Clinicians as service designers? Reflections on current transformation in the UK health services. Paper presented at the 1st Service Design and Innovation Conference on DeThinking Service, ReThinking Design in Oslo, Norway, 24-26 November 2009.

Cipolla, C. \& Bartholo, R. (2014), Empathy or inclusion: A dialogical approach to socially responsible design. International Journal of Design, 8(2), 87-100.

Cottam, H., \& Leadbeater, C. (2004). RED paper 01: Health: Co-creating services. London, United Kingdom: Design Council.

Danaher, T. S., \& Gallan, A. S. (2016). Service research in health care: Positively impacting lives. Journal of Service Research, 19(4), 433-437.

Donetto, S., Pierri, P., Tsianakas, V., \& Robert, G. (2015). Experience-based co-design and healthcare improvement: realizing participatory design in the public sector. The Design Journal, 18(2), 227248.

Ehn, P. (2008). Participation in design things. In Proceedings of the 10th Anniversary Conference on Participatory Design (pp. 92-101). Bloomington, IN: Indiana University.

Farrington, C. J. (2016). Co-designing healthcare systems: between transformation and tokenism. Journal of the Royal Society of Medicine, 109(10), 368-371.

Flick, U. (2018), "Triangulation", in Denzin, N.K. and Lincoln, Y.S. (Eds.), The SAGE Handbook of Qualitative Research, Sage, London, England, pp. 777-804. 
Freire, K., \& Sangiorgi, D. (2010). Service design \& healthcare innovation: From consumption to coproduction and co-creation. Paper presented at the 2nd Nordic Service Design Conference, Linkoping.

Gallan, A. S., McColl-Kennedy, J. R., Barakshina, T., Figueiredo, B., Jefferies, J. G., Gollnhofer, J., Hibbert, S., Luca, S., Roy, S., Spanjol, J., \& Winklhofer, H. (2018). Transforming community wellbeing through patients' lived experiences. Journal of Business Research. 100, 376-391.

Goulding, C. (2005). Grounded theory, ethnography and phenomenology: A comparative analysis of three qualitative strategies for marketing research. European Journal of Marketing, 39(3/4), 294308.

Hargraves, I. (2018). Care and capacities of human-centered design. Design Issues, 34(3), 76-88.

Hussain, S., Sanders, E. B.-N., \& Steinert, M. (2012). Participatory design with marginalized people in developing countries: Challenges and opportunities experienced in a field study in Cambodia. International Journal of Design, 6(2), 91-109.

International Association of Public Participation [IAP2] (2018). IAP2 Spectrum of Public Participation. Retrieved from https://cdn.ymaws.com/www.iap2.org/resource/resmgr/pillars/Spectrum_8.5x11_Print.pdf

Lehoux, P., Hivon, M., Williams-Jones, B., \& Urbach, D. (2011). The worlds and modalities of engagement of design participants: A qualitative case study of three medical innovations. Design Studies, 32(4), 313-332.

Mager, B., Haynes, A., Ferguson, C., Sangiorgi, D., Gullberg, G., \& Jones, M. (2017). Impact and Future Perspectives. In B. Mager (Ed.), Service design impact report: Health sector. Cologne, Germany: Service Design Network.

Malmberg L., Rodrigues V., Lännerström L., Wetter-Edman K., Vink J., \& Holmlid S. (2019). Service design as a transformational driver towards person-centered care in healthcare. In Pfannstiel M. A., Rasche C. (Eds.), Service Design and Service Thinking in Healthcare and Hospital Management; Theory, Concepts and Practice, Springer International Publishing AG, Cham, 1-18.

McColl-Kennedy, J. R., Vargo, S. L., Dagger, T. S., Sweeney, J. C., \& Kasteren, Y. v. (2012). Health care customer value cocreation practice styles. Journal of Service Research, 15(4), 370-389.

McColl-Kennedy, J. R., Snyder, H., Elg, M., Witell, L., Helkkula, A., Hogan, S. J., \& Anderson, L. (2017). The changing role of the health care customer: review, synthesis and research agenda. Journal of Service Management, 28(1), 2-33.

Ocloo, J., \& Matthews, R. (2016). From tokenism to empowerment: progressing patient and public involvement in healthcare improvement. BMJ Qual Saf, 25(8), 626-632.

Oertzen, A.-S., Odekerken-Schröder, G., Brax, S. A., \& Mager, B. (2018). Co-creating servicesconceptual clarification, forms and outcomes. Journal of Service Management, 29(4), 641-679.

Sellen, K. (2017). Problem based learning: Developing competency in knowledge integration in health design. Paper presented at the International Conference on Engineering and Product Design Education in Oslo, Norway, 7-8 September 2017.

Spanjol, J., Cui, A. S., Nakata, C., Sharp, L. K., Crawford, S. Y., Xiao, Y., \& Watson-Manheim, M. B. (2015). Co-production of prolonged, complex, and negative services: An examination of medication adherence in chronically ill individuals. Journal of Service Research, 18(3), 284-302.

Thompson, C. J. (1997). Interpreting consumers: A hermeneutical framework for deriving marketing insights from the texts of consumers' consumption stories. Journal of Marketing Research, 34(4), 438-455.

Thompson, C. J., Locander, W. B., \& Pollio, H. R. (1990). The lived meaning of free choice: An existential-phenomenological description of everyday consumer experiences of contemporary married women. Journal of Consumer Research, 17(3), 346-361. 
Tobiasson, H., Sundblad, Y., Walldius, Å., \& Hedman, A. (2015). Designing for active life: Moving and being moved together with dementia patients. International Journal of Design, 9(3), 47-62.

Trischler, J., Pervan, S. J., Kelly, S. J., \& Scott, D. R. (2018). The value of codesign: The effect of customer involvement in service design teams. Journal of Service Research, 21(1), 75-100.

Vahdat, S., Hamzehgardeshi, L., Hessam, S., \& Hamzehgardeshi, Z. (2014). Patient involvement in health care decision making: a review. Iranian Red Crescent Medical Journal, 16(1), 1-7.

Vink, J., \& Oertzen, A.-S. (2018). Integrating empathy and lived experience through co-creation in service design. Paper presented at the 6th Service Design and Innovation Conference on Proof of Concept in Milano, Italy, 18-20 June.

Williams, F., \& Jeanetta, S. C. (2016). Lived experiences of breast cancer survivors after diagnosis, treatment and beyond: qualitative study. Health Expectations, 19(3), 631-642.

World Health Organization. (2018). WHO Framework on integrated people-centered health services. Retrieved from http://www.who.int/servicedeliverysafety/areas/people-centred-care/en/

Author Bios:

Anna-Sophie Oertzen holds a PhD in Service Design and Innovation. She is a co-creation adept, exploring innovative ways to design and deliver human-centric and profitable applications and solutions, with a coined interest for the healthcare sector.

Josina Vink is Associate Professor of Service Design at the Oslo School of Architecture and Design (AHO). Josina's research focuses on shaping social structures and health systems transformation.

Gaby Odekerken-Schröder is Full Professor in Customer-centric Service Science at the School of Business and Economics of Maastricht University, the Netherlands. Her main research interests are service innovation, service robots, healthcare services, relationship management, customer loyalty, and service failure and recovery.

Birgit Mager is Professor for Service Design at the Köln International School of Design, Institute of the Technical University Cologne, Germany. She is also Co-Founder and President of the International Service Design Network (SDN) and publisher of Touchpoint, the Service Design journal.

Salomé Azevedo is head of Digital Health in Value4Health.CoLAB. She is a Ph.D. student at the Engineering and Management program at IST and a teaching assistant at Católica LSBE. She was Treasurer and platform manager at Patient Innovation.

Acknowledgements: We are grateful to all the interviewees who generously gave their time to participate. We also express our gratitude to the representatives from Patient Innovation and Experio Lab for their openness, critical reflections, and assistance with recruitment. This project has received funding from the European Union's Horizon 2020 research and innovation programme under the Marie Sklodowska-Curie grant agreement No. 642116. 